\title{
Produção de serapilheira e decomposição do material foliar em um cerradão na Estação Ecológica de Jataí, município de Luiz Antônio, SP, Brasil
}

\author{
Marcus Vinicius Cianciaruso ${ }^{1,5}$, José Salatiel Rodrigues Pires², Welington Bráz Carvalho Delitti e \\ Érico Fernando Lopes Pereira da Silva ${ }^{4}$
}

Recebido em 10/11/2003. Aceito em 24/06/2005.

\begin{abstract}
RESUMO - (Produção de serapilheira e decomposição do material foliar em um cerradão na Estação Ecológica de Jataí, município de Luiz Antônio, SP, Brasil). Estimou-se a produção de serapilheira e a taxa de decomposição do material foliar em uma área de cerradão, fisionomia pouco estudada a esse respeito e muito ameaçada, principalmente no Estado de São Paulo. No período de estudo, a quantidade total de serapilheira produzida foi de $5646,9 \mathrm{~kg} \cdot \mathrm{ha}^{-1} \cdot$ ano $^{-1}$, onde a fração 'folhas' teve a maior participação, contribuindo com 4081,2 kg.ha' ${ }^{-1}$.ano ${ }^{-1}$, seguida pela fração 'ramos' (1066,1 kg.ha- ${ }^{-1}$.ano $\left.{ }^{-1}\right)$, 'estruturas reprodutivas' $\left(434,1\right.$ kg.ha ${ }^{-1}$. ano $\left.{ }^{-1}\right)$ e 'miscelânea' $\left(65,5 \mathrm{~kg} \cdot \mathrm{ha}^{-1} \cdot\right.$ ano $\left.^{-1}\right)$. A produção de serapilheira foi altamente estacional e correlacionou-se negativamente com a umidade relativa do ar e com a temperatura média do ar. A produção foliar correlacionou-se negativamente com a umidade do ar, precipitação e temperatura média do ar. Não houve diferença significativa entre a produção de serapilheira desse estudo e a encontrada em duas outras áreas com cerradão e mata mesófila semidecídua, porém essas fisionomias vegetais diferiram significativamente da produção em outra área com cerrado sensu stricto. A taxa de decomposição (K) obtida para o material foliar foi de 0,56 , com o tempo para decomposição de $50 \%$ do material estimado em 1,8 anos e o tempo de renovação do material foliar em 2,3 anos.
\end{abstract}

Palavras-chave : produção de serapilheira, decomposição, cerradão, Estação Ecológica de Jataí

\begin{abstract}
Litter fall and leaf decomposition in cerradão Jataí Reserve, municipality of Luiz Antônio, São Paulo State, Brazil). We estimate litter production and leaf decomposition rate in a cerradão area, physiognomy little studied and very threatened in São Paulo State. During the period of study, litter production was $5646.9 \mathrm{~kg} \cdot \mathrm{ha}^{-1}$.year ${ }^{-1}$, which the 'leaf' fraction corresponded to $4081.2 \mathrm{~kg} \cdot \mathrm{ha}^{-1}$.year ${ }^{-1}$; the 'branch' fraction, to $1066.1 \mathrm{~kg} \cdot \mathrm{ha}^{-1}$.year ${ }^{-1}$; the 'reproductive structures' fraction, to $434.1 \mathrm{~kg} \cdot \mathrm{ha}^{-1}$.year ${ }^{-1}$; and the 'miscellaneous' fraction to $65.5 \mathrm{~kg} \cdot \mathrm{ha}^{-1}$.year ${ }^{-1}$. Litter production was highly seasonal and negatively correlated with relative humidity and air temperature. Leaf production was negatively correlated with relative humidity, rainfall, and air temperature. There was no significant difference between litter production found in this study and those in two other sites with cerradão and semideciduous forest, but these physiognomies differed significantly from the cerrado sensu stricto. Leaf decomposition rate $(\mathrm{K})$ was 0.56 . Half-life of the decomposing material was 1.8 years and turnover time was 2.3 years.
\end{abstract}

Key words: litterfall, litter decomposition, cerradão, Jataí Reserve

\section{Introdução}

Em comparação com outros tipos vegetacionais brasileiros, pode-se dizer que, nas diversas fisionomias de cerrado, estudos a respeito da dinâmica de produção e ciclagem de serapilheira ainda são escassos, com poucas informações sobre a estrutura e funcionamento dessas comunidades, principalmente no estado de São Paulo (Kronka 1998). Em cerradão, a fisionomia florestal do cerrado, há apenas os estudos de Peres et al. (1983) e Guerra-Filho (dados não publicados) sendo, portanto, bastante restritas as investigações para essa fisionomia.

A maior parte das áreas originalmente cobertas por cerradão e que sofreram alguma ação antrópica foram, ao menos, modificadas sem a utilização de um método adequado. Dessa maneira, por não se saber como funciona a dinâmica dessa fisionomia devido à falta de informações básicas, tais modificações podem acarretar grandes perdas quanto ao estoque de nutrien-

\footnotetext{
1 Universidade Federal de São Carlos, Departamento de Botânica, C. Postal 676, CEP 13565-905, São Carlos, SP, Brasil

2 Universidade Federal de São Carlos, Departamento de Hidrobiologia, C. Postal 676, CEP 13565-905, São Carlos, SP, Brasil

3 Universidade de São Paulo, Instituto de Biociências, Departamento de Ecologia Geral, Rua do Matão, Travessa 14, 321, CEP 05508-900, São Paulo, SP, Brasil

4 Universidade Estadual de Campinas, Instituto de Biologia, Departamento de Botânica, C. Postal 6109, CEP 13084971, Campinas, SP, Brasil

5 Autor para correspondência: mcianciaruso@email.com
} 
tes vitais à sua manutenção (Herrera et al. 1981).

Quando os nutrientes são continuamente extraídos do solo pelas plantas ou pela água das chuvas, a velocidade com que essa perda é reposta é fator chave para o ajuste da produtividade (Babbar \& Ewol 1989), visto que para sua manutenção, as comunidades dependem de sua capacidade para circular e acumular os nutrientes existentes nos diferentes compartimentos. Nesse sentido, a produção e a decomposição de serapilheira são processos fundamentais à manutenção da ciclagem de nutrientes, sendo este o aspecto mais estudado e geralmente associado com a quantificação dos nutrientes que retornam ao solo pela decomposição. $\mathrm{O}$ conhecimento desses processos é valioso instrumento para estudos de diagnose ambiental e de avaliação de impactos naturais ou antrópicos, permitindo a comparação de comunidades por meio de parâmetros quantitativos de seu funcionamento (Leitão Filho 1993).

A serapilheira é constituída por materiais vegetais depositados na superfície do solo, tais como folhas, cascas, ramos, troncos, gravetos, flores, inflorescências, frutos, sementes e fragmentos vegetais não identificáveis. Sua deposição introduz heterogeneidade temporal e espacial ao ambiente, podendo afetar a estrutura e a dinâmica da comunidade vegetal (Facelli \& Pickett 1991). O padrão anual de produção de serapilheira é bastante diversificado, desde a queda total do material em curto período em florestas decíduas típicas, até o fluxo contínuo de detritos da biomassa aérea para o solo em florestas sempreverdes. No entanto, as situações intermediárias são mais freqüentes, sendo comuns os locais em que ocorre produção de material durante todo ano, com períodos de maior ou menor intensidade, relacionados a fatores ambientais e/ou genéticos (Delitti, dados não publicados).

A quantidade de serapilheira acumulada varia de acordo com a comunidade e também com o seu estádio sucessional (Olson 1963; Ewel 1976). O equilíbrio é atingido quando a quantidade de material adicionado é igual à quantidade decomposta (Whittaker 1975; Singh \& Gupta 1977), podendo ocorrer, entretanto, variações estacionais nesse compartimento em decorrência da periodicidade da vegetação e/ou da estacionalidade climática (Olson 1963; Meguro et al. 1979; Pagano 1989; Villela \& Proctor 1999).

As diferentes frações da serapilheira têm estrutura e composição química distintas e, portanto, decompõem em diferentes velocidades. Assim, a velocidade global de decomposição dependerá também da proporção relativa dos diferentes componentes presentes. $\mathrm{O}$ material foliar é seguramente o mais importante constituinte da serapilheira nas comunidades florestais (Bray \& Gorham 1964; Delitti, dados não publicados), sendo a fração mais bem estudada e tendo sido utilizada para comparações entre os resultados dos diversos estudos dessa natureza.

Entre os fatores que controlam a decomposição destacam-se a composição química do substrato, principalmente a quantidade de substâncias lixiviáveis e solúveis em água, as condições ambientais como temperatura, precipitação, evapotranspiração real, umidade, aeração e estrutura do solo, além das características anatômicas e os conteúdos de energia (Singh \& Gupta 1977; Meguro et al. 1980). Outro fator a ser considerado é a composição da comunidade detritívora e sua afinidade pelo substrato.

Nesse estudo, quantificou-se a produção de serapilheira e suas frações - folhas, ramos, estruturas reprodutivas e miscelânea - durante o período de um ano; estimou-se a taxa de decomposição do material foliar por meio da constante de decomposição $(\mathrm{K})$ (Olson 1963), bem como o tempo necessário para a ciclagem deste material (Rochow 1974) e para 50\% de sua decomposição (Hopkins 1966). Procurou-se também verificar se a produção de serapilheira do presente estudo diferia significativamente da produção encontrada em cerradão (Peres et al. 1983), cerrado sensu stricto (Peres et al. 1983) e em floresta mesófila semidecídua (Martins \& Rodrigues 1999). Finalmente buscou-se verificar a correlação entre a estacionalidade dessa produção e as variáveis climáticas de precipitação, temperatura média do ar, umidade relativa do ar e insolação (horas de luminosidade).

\section{Material e métodos}

Área de estudo - A Estação Ecológica de Jataí (EEJ) está localizada no município de Luiz Antônio, região nordeste do Estado de São Paulo, entre as coordenadas $21^{\circ} 30^{\prime} \mathrm{S}$ e $47^{\circ} 50^{\prime} \mathrm{W}$. O entorno imediato da área é caracterizado por intensa atividade silvicultural (Eucalyptus sp.), existindo ainda algumas áreas de monocultura de cana-de-açúcar e pastagem. A EEJ é uma das maiores regiões florestadas do interior do Estado de São Paulo de interesse para a preservação, devido à diversidade de espécies e hábitats (Pires, dados não publicados). No plano de manejo conceitual para o Parque Estadual de Jataí, a área do presente estudo foi considerada como parte da Zona Intangível (ZIN) e primitiva no zoneamento proposto, por se tratar de fragmento florestal de vital importância para conexão com a Reserva de Cerrado Pé-de-Gigante 
(Pires, dados não publicados). Apesar de seu importante papel na conservação da biodiversidade regional, é área sujeita a influência antrópica, como caça e coleta de produtos vegetais, entre outros, devido à falta de fiscalização (Pires 2000).

As condições climáticas da região permitem classificá-la como pertencente ao clima Aw de Köppen (Setzer 1966), ou Tropical do Brasil Central (Nimer 1977), com as temperaturas mais elevadas ocorrendo no período de maior precipitação e as menores, no período de menor precipitação (Santos \& Mozeto 1992). As maiores precipitações ocorrem nos meses de dezembro, janeiro e fevereiro - o período chuvoso vai de novembro a abril - e as menores encontram-se nos meses de junho a agosto - o período seco vai de maio a outubro (Santos \& Mozeto 1992). Na área de estudo, predomina o solo do tipo Latossolo-VermelhoAmarelo, com a ocorrência de manchas de Areia Quartzoza. O solo pode ser caracterizado como ácido $(\mathrm{pH}=3,75 \pm 0,02)$, distrófico, álico, deficiente em fósforo, cálcio e magnésio e com pouca disponibilidade de nitrogênio, havendo predominância da forma $\mathrm{NH}_{4}^{+}$ sobre a forma $\mathrm{NO}_{3}{ }^{-}$(Pereira-Silva, dados não publicados).

Pereira-Silva (dados não publicados), em levantamento bibliográfico sobre o histórico de uso da área da Estação Ecológica de Jataí, relatou a retirada, no passado, de espécies de interesse comercial para construção de moirões e dormentes. Pereira-Silva et al. (2004) caracterizaram a fisionomia da área como cerradão, com a ocorrência de espécies que são verificadas tanto no cerradão quanto na floresta estacional semidecídua. Assim, espécies como Casearia sylvestris Sw., Byrsonima intermedia A. Juss., Amaioua guianensis Aubl., Copaifera langsdorffii Desf., Terminalia brasiliensis Camp., Guapira opposita Vell., Senna rugosa (G. Don.) Irwin \& Barneby, Siparuna guianensis Aubl. e Machaerium acutifolium Vogel contribuem para a riqueza florística da vegetação do cerradão na área (Pereira-Silva et al. 2004).

Coletas - Realizou-se a primeira campanha de campo no início de agosto/2001, quando se estabeleceu os coletores e as bolsas decompositoras na área de estudo. $\mathrm{O}$ intervalo entre as coletas de serapilheira foi mensal e terminou na primeira semana de agosto/2002, quando se completou um ano de coletas.

Distribuiu-se de forma sistemática 24 coletores de $50 \times 50 \mathrm{~cm}\left(0,25 \mathrm{~m}^{2}\right.$ de área de coleta $)$ e $20 \mathrm{~cm}$ alt. em uma transecção de aproximadamente $1.800 \mathrm{~m}$, cortando o fragmento de estudo da borda leste à oeste.
O primeiro e o último coletor estavam a $100 \mathrm{~m}$ das respectivas bordas (a fim de evitar possíveis efeitos de borda). Os outros coletores estavam dispostos ora para direita, ora para esquerda - a aproximadamente $72 \mathrm{~m}$ de distância entre si na transecção.

Mensalmente, recolheu-se e acondicionou-se todo o material acumulado em sacos plásticos para posterior triagem em laboratório. Separou-se manualmente o material de cada coletor em quatro frações: folhas, ramos, estruturas reprodutivas (flores, inflorescências, frutos e sementes) e miscelânea (material vegetal particulado e não identificado). Descartou-se qualquer material que não fosse de origem vegetal. Posteriormente, levou-se cada fração à estufa a $80^{\circ} \mathrm{C}$ até obtenção de peso seco constante. Após obtenção do peso seco, pesou-se as frações de cada coletor em balança analítica.

Coletou-se folhas recém-caídas e em bom estado de conservação para possibilitar melhor homogeneização da amostra quanto ao estádio de decomposição inicial do material no solo e levou-se à estufa a $60^{\circ} \mathrm{C}$ até a obtenção do peso seco constante. Após a secagem pesou-se esse material em balança analítica e encerrou-se 5,0 g (peso seco inicial) em cada bolsa decompositora. As bolsas decompositoras são bolsas de náilon ( $2 \mathrm{~mm}$ de poro) de $20 \times 20 \mathrm{~cm}$ (Bocock \& Gilbert 1957). Sistematicamente, na mesma transecção dos coletores, colocou-se sobre a serapilheira acumulada no solo 120 bolsas decompositoras. Retirou-se as bolsas do cerradão nos meses de setembro, outubro e novembro/2001 e fevereiro, julho e agosto/2002. Em cada coleta, recolheu-se do campo um grupo de 20 bolsas decompositoras.

No laboratório, retirou-se qualquer material que estivesse preso externamente às bolsas antes de cuidadosamente abri-las. Limpou-se o material foliar com um pincel de cerdas macias - para retirada de solo, raízes, partículas animais e outras impurezas - e levou-se o mesmo para secagem em estufa a $80^{\circ} \mathrm{C}$ até obtenção do peso seco constante. Foi pesado o material foliar de cada bolsa decompositora em balança analítica e anotados os valores obtidos em gramas.

Calculou-se os coeficientes de decomposição $\mathrm{K}$ e K' a partir das equações propostas por Olson (1963) e estimou-se o tempo de ciclagem ou renovação do material (Rochow 1974) e o tempo de decomposição de 50\% do material (Hopkins 1966).

Após verificação de que os dados distribuíam-se normalmente $(p>0,10)$ pelo teste de KolmogorovSmirnov (Zar 1999), aplicou-se a análise de variância (Andeva) de medidas repetidas e o teste de Tukey 
(Zar 1999) comparando a produção de serapilheira (total e frações) entre os meses para verificar possível diferença estatística nas produções mensais. Comparou-se os dados brutos da produção anual de serapilheira deste trabalho com os valores obtidos por Peres et al. (1983), para cerradão e cerrado sensu stricto no Planalto Central (próximo a Brasília) e por Martins \& Rodrigues (1999), em uma floresta mesófila semidecídua da Reserva Municipal de Santa Genebra (Campinas, SP) por meio de Andeva (um critério) e do teste de Tukey (Zar 1999). Neste caso, os dados utilizados foram os totais mensais de cada trabalho no período de um ano. Finalmente, para verificar possível correlação entre os dados de produção de serapilheira e suas frações e os dados climáticos de precipitação, temperatura média do ar, umidade relativa do ar e insolação (horas de luminosidade), utilizou-se o teste de correlação de Pearson (Zar 1999). A fração 'miscelânea' não foi incluída nas análises, visto que geralmente é pouco expressiva na composição da serapilheira e considerada apenas resíduo.

Os valores encontrados para a decomposição também passaram no teste de normalidade Kolmogorov-Smirnov ( $p$ > 0,05) (Zar 1999). Aplicou-se a Andeva (um critério) e o teste de Tukey (Zar 1999), comparando os valores referentes aos períodos de coleta para verificar possível diferença estatística entre os mesmos. Calculou-se ainda a curva de regressão exponencial para os valores da biomassa foliar remanescente encontrada a cada coleta nas bolsas decompositoras (Zar 1999).

\section{Resultados}

Os dados meteorológicos obtidos na Estação Meteorológica de São Simão (2129'S e 47³3’W) para o período de estudo confirmam a classificação do clima da região como sendo do tipo Aw de Köppen - tropical úmido, com a estação seca no inverno - ou Tropical do Brasil Central, segundo classificação de Nimer (1977). O total de precipitação pluviométrica no período de estudo foi de $1.684,2 \mathrm{~mm}$. Os maiores valores foram registrados nos meses de janeiro $(370,8 \mathrm{~mm})$ e fevereiro $(363,4 \mathrm{~mm})$ e os menores, nos meses de junho $(0,0 \mathrm{~mm})$ e julho $(0,7 \mathrm{~mm})$. $\mathrm{O}$ valor médio da temperatura do ar para o período foi de $22,7^{\circ} \mathrm{C}$, praticamente equivalente à temperatura média anual para a região $\left(22,8^{\circ} \mathrm{C}\right)$. A maior temperatura média ocorreu no mês de março $\left(25^{\circ} \mathrm{C}\right)$ e a menor, no mês de julho $\left(18,9^{\circ} \mathrm{C}\right)$, indicando baixa variação ao longo do ano. O mês de abril teve a maior insolação (301,5 horas) e fevereiro, a menor
(142,5 horas). A umidade relativa do ar na região se manteve o ano todo acima dos $56 \%$, sendo agosto o mês de menor valor (56\%) e fevereiro, o de maior (80\%). O diagrama climático elaborado pelo sistema de Walter (Walter 1986) mostrou a existência de uma estação seca compreendendo os meses de agosto/2001 e abril, maio, junho e julho/2002 (Fig. 1).

A quantidade total de serapilheira produzida foi de $5.646,9 \mathrm{~kg} \cdot \mathrm{ha}^{-1}$. ano ${ }^{-1}$, onde a fração 'folhas' teve a maior participação, contribuindo com 4.081,2 kg.ha- ${ }^{-1} \cdot \mathrm{ano}^{-1}$, seguida pela fração 'ramos' $\left(1.066,1 \mathrm{~kg} \cdot \mathrm{ha}^{-1} \cdot \mathrm{ano}^{-1}\right)$; 'estruturas reprodutivas' (434,1 kg.ha- ${ }^{-1} \cdot$ ano $\left.^{-1}\right)$ e 'miscelânea' (65,5 kg.ha ${ }^{-1} \cdot$ ano $\left.^{-1}\right)$. A Tab. 1 apresenta os dados das produções mensais de serapilheira (total e frações) de maneira a possibilitar a comparação com outros trabalhos.

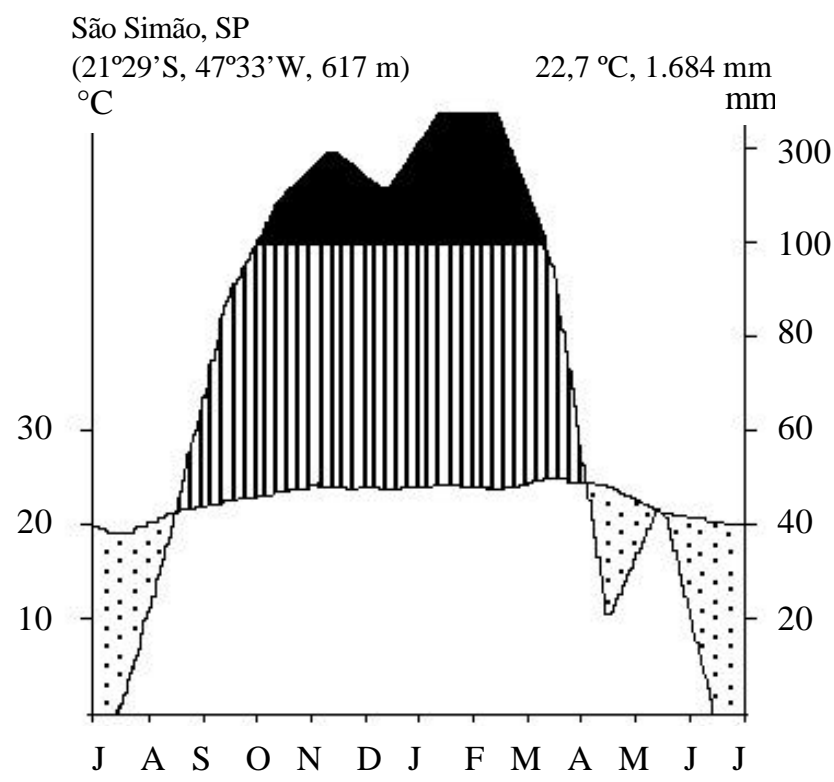

Figura 1. Diagrama climático segundo Walter (1986), construído a partir dos dados obtidos da Estação Meteorológica de São Simão, SP, Brasil no período de julho/2001 a julho/2002.

A menor participação da fração 'folhas' ocorreu em janeiro e a maior, em agosto (Tab. 1). A fração 'ramos' foi a segunda em importância, com maior expressão no mês de janeiro e menor, no mês de março (Tab. 1). A fração 'estruturas reprodutivas' teve maior participação nos meses de dezembro e janeiro e a menor, no mês de julho (Tab. 1).

Observou-se clara estacionalidade na produção de serapilheira (Fig. 2), com as maiores produções ocorrendo nos meses de agosto/2001, setembro/2001 e julho/2002 (847,7 kg.ha ${ }^{-1}, 682,3 \mathrm{~kg} \cdot \mathrm{ha}^{-1}$ e $1049,7 \mathrm{~kg} \cdot \mathrm{ha}^{-1}$, respectivamente). Esses três meses 
Tabela 1. Produção de serapilheira (total e frações em kg.ha ${ }^{-1} \cdot \mathrm{mês}^{-1}$ ) no período de agosto/2001 a julho/2002, em um cerradão da Estação Ecológica de Jataí, Luiz Antônio, SP, Brasil.

\begin{tabular}{|c|c|c|c|c|}
\hline Mês/Ano & Folhas & Ramos & $\begin{array}{c}\text { Estruturas } \\
\text { reprodutivas }\end{array}$ & Total \\
\hline Agosto/2001 & $701,9(82,8 \%)$ & $109,3(12,9 \%)$ & $31,1 \quad(3,7 \%)$ & 847,7 \\
\hline Setembro/2001 & $383,7(56,2 \%)$ & $180,1 \quad(26,4 \%)$ & $95,8(14,0 \%)$ & 682,3 \\
\hline Outubro/2001 & $330,9(70,7 \%)$ & $87,6(18,7 \%)$ & $38,7 \quad(8,3 \%)$ & 467,7 \\
\hline Novembro/2001 & $257,1(65,9 \%)$ & $102,2(26,2 \%)$ & $28,2 \quad(7,2 \%)$ & 389,9 \\
\hline Dezembro/2001 & $188,3(56,8 \%)$ & $59,2(17,9 \%)$ & $75,7(22,8 \%)$ & 331,2 \\
\hline Janeiro/2002 & $116,3(50,6 \%)$ & $68,1 \quad(29,6 \%)$ & $42,2(18,3 \%)$ & 229,9 \\
\hline Fevereiro/2002 & $148,8(70,0 \%)$ & $26,0(12,2 \%)$ & $35,6(16,8 \%)$ & 212,4 \\
\hline Março/2002 & $344,4(82,5 \%)$ & $43,3(10,3 \%)$ & $25,7 \quad(6,2 \%)$ & 417,3 \\
\hline Abril/2002 & $284,2(80,8 \%)$ & $47,1 \quad(13,4 \%)$ & $18,6 \quad(5,3 \%)$ & 351,8 \\
\hline Maio/2002 & $248,3(80,5 \%)$ & $44,9(14,6 \%)$ & $14,1 \quad(4,5 \%)$ & 308,5 \\
\hline Junho/2002 & $282,1 \quad(78,7 \%)$ & $60,9(16,9 \%)$ & $12,8 \quad(3,5 \%)$ & 358,5 \\
\hline Julho/2002 & $795,2(75,8 \%)$ & $237,4(22,6 \%)$ & $15,6 \quad(1,5 \%)$ & 1049,7 \\
\hline Total & $4081,2(72,3 \%)$ & $1066,1(18,9 \%)$ & $434,1 \quad(7,7 \%)$ & 5646,9 \\
\hline
\end{tabular}

somaram 45,7\% da produção total. A grande produção em agosto e setembro seguiu-se por considerável diminuição em outubro e a partir daí, uma gradativa diminuição mensal até janeiro e fevereiro/2002. Em março, houve relativo aumento na produção que se manteve praticamente constante até junho, com notável aumento em julho/2002.

A partir da Andeva de medidas repetidas verificou-se que, no período de estudo, a produção de serapilheira entre os meses foi significativamente diferente $(\mathrm{F}=16,690, \mathrm{p}=0,0001)$ e evidenciou-se dois

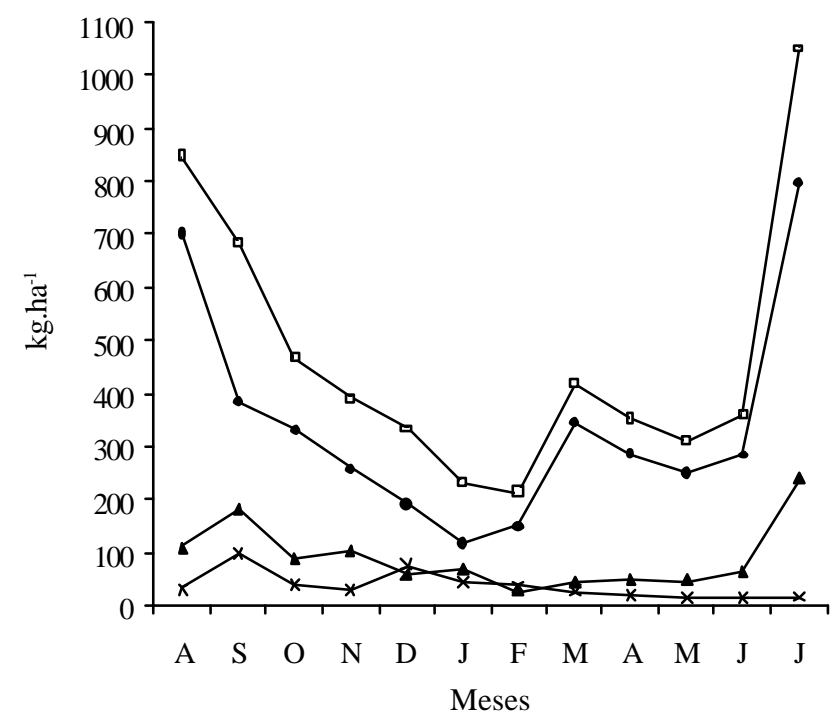

Figura 2. Produção mensal de serapilheira total ( $\square$ ), folhas ramos $(\boldsymbol{\Delta})$ e estruturas reprodutivas $(\times)$ em kg.ha ${ }^{-1}$, no período de agosto/2001 a julho/2002, em um cerradão da Estação Ecológica de Jataí, Luiz Antônio, SP, Brasil. grandes grupos distintos. O primeiro grupo foi formado pelos meses de maior produção (agosto/2001 e julho/2002) e representou 33,6\% da produção no período. Esses meses tiveram produções estatisticamente diferentes dos outros meses ( $\mathrm{p}<0,01)$, mas não tiveram produção significativamente diferente entre si ( $p>0,05)$, com exceção de agosto, que não diferiu de setembro $(p>0,05)$. Considerou-se a produção de setembro como transitória entre os dois grandes grupos formados, visto que sua produção não foi significativamente diferente dos meses de outubro $(p>0,05)$, novembro $(p>0,05)$ e março $(p>0,05)$, ao mesmo tempo em que diferiu do mês de julho $(\mathrm{p}<0,01)$. $\mathrm{O}$ segundo grupo foi formado pelos meses restantes que não apresentaram produções significativamente diferentes entre si $(p>0,05)$, que representam o período de transição entre dois extremos claros na dinâmica da serapilheira: a maior produção no período da estação seca (agosto/2001 e julho/2002) e a menor no período da estação chuvosa (dezembro/2001, janeiro e fevereiro/2002).

Verificou-se que, no período de estudo, a produção da fração foliar foi significativamente diferente entre os meses $(F=24,837, p<0,001)$. Novamente, encontrou-se dois grupos bem distintos. $\mathrm{O}$ primeiro, foi formado pelos meses de maior produção (agosto/2001 e julho/2002) que juntos representaram $36,8 \%$ da produção total. Esses meses tiveram produções estatisticamente diferentes dos outros meses $(\mathrm{p}<0,01)$, mas não diferiram significativamente entre si $(q=2,246, p>0,05)$. O segundo, foi formado pelos meses restantes. A fração foliar teve maior pico de 
produção em julho/2002 e menor, janeiro/2002 (Tab. 1).

A produção da fração ramos foi significativamente diferente entre os meses $(\mathrm{F}=3,026, \mathrm{p}<0,001)$. A maior produção ocorreu em julho/2002 e a menor, em fevereiro/2002 (Tab. 1). A produção da fração estruturas reprodutivas também foi significativamente diferente entre os meses ( $\mathrm{F}=5,428, \mathrm{p}<0,001)$, apresentando dois grandes picos de produção, em setembro e dezembro (Fig. 2). A produção de setembro foi significativamente diferente de todos os outros meses ( $p<0,01)$, não diferindo apenas de dezembro $(q=1,841, p>0,05)$. O menor valor para essa fração foi encontrado em junho/2002 (Tab. 1).

Ao se calcular o coeficiente de correlação de Pearson (r) entre as variáveis climáticas e os valores de produção mensal de serapilheira, verificou-se correlação negativa com a umidade relativa do ar e com a temperatura média do ar (Tab. 2), ou seja, quando a umidade relativa do ar e a temperatura apresentaram os maiores valores (estação úmida), a produção de serapilheira foi menor e quando apresentaram os valores mais baixos (estação seca), a produção foi maior. A fração foliar apresentou correlação negativa com os valores de precipitação, umidade relativa do ar e temperatura média do ar (Tab. 2). Assim, para essa fração, pode-se considerar que, quanto maiores os valores de precipitação, umidade relativa do ar e temperatura média do ar, menor a produção e que, quanto menor esses valores, maior a produção. Para a fração 'ramos' encontrou-se apenas correlação negativa com a temperatura (Tab. 2). Não se encontrou correlação significativa para a fração 'estruturas reprodutivas' com as variáveis climáticas estudadas (Tab. 2).

Comparou-se os dados brutos obtidos para a produção de serapilheira desse trabalho com os dados brutos obtidos para cerrado sensu stricto e cerradão
(Peres et al. 1983) e mata mesófila semidecídua (Martins \& Rodrigues 1999).

A produção do cerrado sensu stricto (Peres et al. 1983) diferiu significativamente das produções encontradas no cerradão (Peres et al. 1983), na mata mesófila semidecídua (Martins \& Rodrigues 1999) e nesse estudo $(\mathrm{p}=0,001, \mathrm{p}=0,017$ e $\mathrm{p}=0,029$, respectivamente).

Não houve diferença entre a produção encontrada neste estudo com as verificadas por Peres et al. (1983), em cerradão, e por Martins \& Rodrigues (1999) em mata mesófila semidecídua $(\mathrm{p}=0,39$ e $\mathrm{p}=0,99$, respectivamente). Também não houve diferença entre a produção encontrada em cerradão (Peres et al. 1983) e a verificada por Martins \& Rodrigues (1999) na mata mesófila semidecídua $(\mathrm{p}=0,470)$.

Decomposição - O processo de decomposição do material foliar ocorreu com maior intensidade nos primeiros meses, com perda de $33,6 \%$ da massa inicial. Nos meses subseqüentes, houve decomposição mais lenta e mais ou menos constante, sendo que, ao final de um ano, apenas $43 \%$ da massa original foi decomposta (Fig. 3). Os valores do peso seco final, obtidos das bolsas decompositoras em cada período, foram significativamente diferentes $(F=65,486, p<0,001)$. Porém não houve diferença significativa para os valores dos dois primeiros meses $(q=1,733, p>0,05)$ e nem para os valores dos últimos dois meses $(q=0,437, p>0,05)$.

Com o peso seco médio da biomassa recolhida nas bolsas decompositoras calculou-se a curva de regressão para o processo. Essa foi do tipo exponencial $\left(\mathbf{R}^{2}=0,95, \mathrm{p}<0,001\right)$ (Fig. 3). A taxa de decomposição $\mathrm{K}$ obtida para o período foi de 0,56 , sendo que o tempo para decomposição de $50 \%$ do material foi estimado em 1,8 anos, e o tempo de renovação ou ciclagem do material foliar foi estimado em 2,3 anos $\left(K^{\prime}=0,23\right)$.

Tabela 2. Valores dos coeficientes de correlação de Pearson entre as produções mensais de serapilheira (total e frações) e as variáveis climáticas mensais de precipitação média mensal, umidade relativa do ar, insolação (horas de luminosidade) e temperatura média do ar, no período de agosto/2001 a julh/2002, em um cerradão da Estação Ecológica de Jataí, Luiz Antônio, SP, Brasil. N = 12.

\begin{tabular}{lllll}
\hline & $\begin{array}{c}\text { Precipitação média } \\
\text { mensal }\end{array}$ & $\begin{array}{c}\text { Umidade relativa } \\
\text { do ar }\end{array}$ & $\begin{array}{c}\text { Insolação } \\
\text { (horas) }\end{array}$ & $\begin{array}{c}\text { Temperatura média } \\
\text { do ar }\end{array}$ \\
\hline Serapilheira total & $\mathrm{r}=-0,55$ & $\mathrm{r}=-0,74$ & $\mathrm{r}=0,35$ & $\mathrm{r}=-065$ \\
Folhas & $\mathrm{p}=0,063$ & $\mathrm{p}=0,005$ & $\mathrm{p}=0,250$ & $\mathrm{p}=0,020$ \\
& $\mathrm{r}=-0,62$ & $\mathrm{r}=-0,72$ & $\mathrm{r}=0,47$ & $\mathrm{r}=-0,67$ \\
Ramos & $\mathrm{p}=0,030$ & $\mathrm{p}=0,007$ & $\mathrm{p}=0,115$ & $\mathrm{p}=0,016$ \\
& $\mathrm{r}=-0,32$ & $\mathrm{r}=0,57$ & $\mathrm{r}=0,09$ & $\mathrm{r}=-0,58$ \\
Estruturas reprodutivas & $\mathrm{p}=0,298$ & $\mathrm{p}=0,052$ & $\mathrm{p}=0,7700$ & $\mathrm{p}=0,049$ \\
& $\mathrm{r}=0,27$ & $\mathrm{r}=-0,09$ & $\mathrm{r}=-0,47$ & $\mathrm{r}=0,26$ \\
& $\mathrm{p}=0,380$ & $\mathrm{p}=0,770$ & $\mathrm{p}=0,117$ & $\mathrm{p}=0,400$ \\
\hline
\end{tabular}




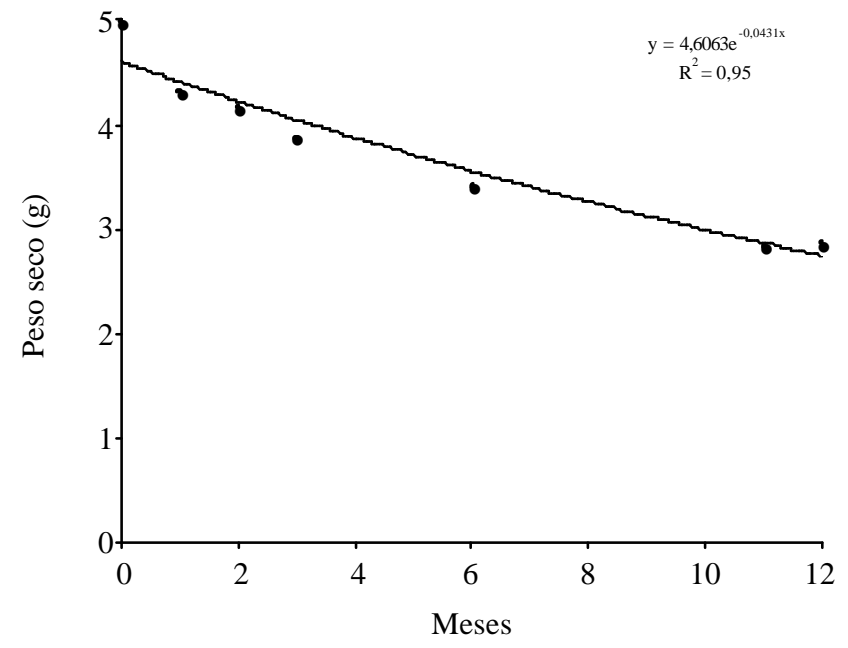

Figura 3. Peso seco final (g) do material foliar recolhido das bolsas decompositoras e a respectiva linha de tendência exponencial $\left(\mathrm{R}^{2}=0,95, \mathrm{p}<0,001\right)$, no período de agosto/2001 a julho/2002, em um cerradão da Estação Ecológica de Jataí, Luiz Antônio, SP, Brasil.

\section{Discussão}

Produção de serapilheira - Os valores de produção de serapilheira conhecidos para o Brasil (Tab. 3) exemplificam claramente o caráter variado do processo dessa produção, que deve ser analisado levando em conta a interação de fatores climáticos, edáficos e biológicos (Delitti, dados não publicados). Os valores encontrados neste trabalho para as frações estão de acordo com o observado na literatura (Bray \& Gorham 1964; Ewel 1976; Delitti, dados não publicados; 1998; Silva, dados não publicados; Peres et al. 1983; Martins \& Rodrigues 1999), em que a fração foliar é a principal constituinte do total de biomassa produzida, sendo seguida, na seqüência, pela fração ramos, estruturas reprodutivas e miscelânea.

Os períodos de maior produção de serapilheira são freqüentemente relacionados à diminuição do fotoperíodo e/ou a períodos de deficiência hídrica (Bray \& Gorham 1964). Com os resultados obtidospelas análises de correlação entre as variáveis climáticas e a produção de serapilheira, pode-se observar que apenas a umidade relativa do ar e a temperatura média do ar tiveram correlação significativa com essa produção. Martins \& Rodrigues (1999), em floresta mesófila semidecídua, encontraram correlação negativa entre a produção de serapilheira e a umidade relativa do ar ( $\mathrm{r}=-0,68, \mathrm{p}<0,05)$, e correlação positiva com a velocidade média do vento $(\mathrm{r}=0,75, \mathrm{p}<0,01)$, variável não analisada neste trabalho.

Assim, observou-se que as curvas de umidade relativa do ar e temperatura média do ar são antagônicas com a produção de serapilheira, visto que, quando as primeiras aumentam, a última tende a

Tabela 3. Produção de serapilheira em algumas formações vegetais brasileiras.

\begin{tabular}{|c|c|c|c|c|}
\hline Local & Tipo vegetacional & Latitude & $\begin{array}{c}\text { Produção } \\
\left(\mathrm{kg} \cdot \mathrm{ha}^{-1} \cdot \mathrm{ano}^{-1}\right)\end{array}$ & Autores \\
\hline Ilha Sta. Catarina & Mata Atlântica & $27^{\circ} 35^{\prime} \mathrm{S}$ & 6370 & Hinkel \& Panitz 1999 \\
\hline Blumenau/SC & Mata Atlântica & $26^{\circ} 53^{\prime} \mathrm{S}$ & 9560 & Vibrans \& Sevegnani 2000 \\
\hline Ilha do Cardoso & Mata Atlântica & $25^{\circ} \mathrm{S}$ & 6300 & Moraes et al. 1999 \\
\hline Ilha do Cardoso & Restinga & $25^{\circ} \mathrm{S}$ & 3900 & Moraes et al. 1999 \\
\hline São Paulo/SP & Fl. Mesófila Semidecídua & - & 9410 & Meguro et al. 1979 \\
\hline Tejupá/SP & Cerradão & $23^{\circ} 20^{\prime} \mathrm{S}$ & 6120 & $\begin{array}{l}\text { Guerra-Filho, dados não } \\
\text { publicados }\end{array}$ \\
\hline Anhembi/SP & Fl. Mesófila Semidecídua & $23^{\circ} \mathrm{S}$ & 8800 & Cesar 1993 \\
\hline Campinas/SP & Fl. Mesófila Semidecídua & $22^{\circ} 49^{\prime} \mathrm{S}$ & 5968 & Martins \& Rodrigues 1999 \\
\hline Rio Claro/SP & Fl. Mesófila Semidecídua & $22^{\circ} 22^{\prime} \mathrm{S}$ & 8643 & Pagano 1989 \\
\hline Mogi-Guaçu/SP & Campo cerrado & $22^{\circ} 18^{\prime} \mathrm{S}$ & 3210 & $\begin{array}{l}\text { Delitti, dados não } \\
\text { publicados }\end{array}$ \\
\hline T. Sampaio/SP & Fl. Mesófila Semidecídua & $22^{\circ} \mathrm{S}$ & 6560 & Schlittler et al. 1993 \\
\hline Luiz Antônio/SP & Cerradão & $21^{\circ} 35^{\prime} \mathrm{S}$ & 5647 & Esse estudo \\
\hline Ouro Preto/MG & Fl. Mesófila Semidecídua & $20^{\circ} 23^{\prime} \mathrm{S}$ & 6780 & Werneck et al. 2001 \\
\hline Brasília/DF & Cerradão & $15^{\circ} \mathrm{S}$ & 7800 & Peres et al. 1983 \\
\hline Brasília/DF & Cerrado sensu stricto & $15^{\circ} \mathrm{S}$ & 2100 & Peres et al. 1983 \\
\hline Brasília/DF & Cerrado & $15^{\circ} \mathrm{S}$ & 2415 & Silva, dados não publicados \\
\hline Recife/PE & Mata Atlântica & $08^{\circ} \mathrm{S}$ & 6400 & Sampaio et al. 1988 \\
\hline Manaus/AM & Floresta Amazônica & $03^{\circ} \mathrm{S}$ & 5040 & Dantas \& Phillipson 1989 \\
\hline Ilha de Maracá/RO & & $03^{\circ} 22^{\prime} \mathrm{N}$ & 8600 & Villela \& Proctor 1999 \\
\hline Ilha de Maracá/RO & & $03^{\circ} 22^{\prime} \mathrm{N}$ & 9280 & Scott et al. 1992 \\
\hline
\end{tabular}


diminuir, indicando a possível resposta da vegetação a períodos de baixa umidade relativa do ar e temperatura média do ar mais elevada.

No cerrado, muitos autores têm notado grande queda foliar de espécies lenhosas durante a estação seca (Rizzo et al. 1971; Barro \& Caldas 1980; Paulilo $\&$ Felippe 1992). Ambientes com uma estação seca bem definida, geralmente apresentam queda de folhas concentrada nessa época do ano (Monasterio \& Sarmiento 1976; Morellato et al. 1989; Villela \& Proctor 1999). Rizzo et al. (1971) observaram que 90\% das espécies de uma região de cerrado no estado de Goiás apresentam o máximo de perda de folhas em setembro. Barros \& Caldas (1980) observaram acentuada queda de folhas entre maio e junho em espécies de cerrado em Brasília, e Mantovani \& Martins (1988) verificaram que, na reserva de cerrado de Mojiguaçu (SP), o máximo de queda foliar ocorre no final de agosto e início de setembro. De Paula (dados não publicados) em um cerrado sensu stricto, encontrou maior intensidade de queda de folhas no período de menor pluviosidade, o qual também era o período de menor umidade relativa do ar, como constatado nesse estudo.

Diversas teorias têm sido elaboradas para tentar explicar as possíveis causas da queda foliar. Alguns autores sugerem que a abscisão foliar é estimulada pelo déficit hídrico provocado pela escassez de chuvas durante períodos secos (Borchet 1980; Reich \& Borchet 1984). Muitos estudos têm demonstrado que as espécies do cerrado, mesmo aquelas que supostamente têm acesso à água do solo, sofrem restrições hídricas durante o período seco (Moraes et al. 1989; Perez \& Moraes 1991; Moraes \& Prado 1998). Nessas espécies, portanto, a queda das folhas pode ser uma estratégia para reduzir a superfície transpirante, evitando ou tolerando a seca. Para Jackson (1978), a estacionalidade de produção de folhas novas e de produção de serapilheira refletem estratégias de resistência a fatores de tensão ambiental, associadas ao aproveitamento máximo dos recursos ambientais.

A senescência foliar é processo ativo que envolve série de complexas alterações metabólicas na estrutura foliar a cair (Dale 1982), durante o qual pode, muitas vezes, ocorrer a translocação de nutrientes minerais e mesmo de carboidratos e proteínas, representando importante estratégia de conservação de elementos essenciais na biomassa (Duvigneaud \& Denayer-De Smet 1969; Witkamp \& Ausmus 1976; Villela \& Proctor 1999). Chabot \& Hicks (1982) citaram que folhas individuais sofrem abscisão por razões que incluem além de danos físicos, estresses causados por baixas temperaturas e/ou déficit hídrico que promovem desordem na atividade celular induzindo a senescência, ou por indução hormonal provocada pelo próprio programa genético da planta. Portanto, o comportamento estacional da produção de serapilheira decorre, principalmente, do comportamento da fração foliar, visto que esta é a constituinte mais importante da serapilheira e que apresenta resposta mais definida às condições climáticas (Bray \& Gorham 1964; Delitti, dados não publicados). Os presentes resultados corroboram os autores acima, já que se verificou que a fração foliar foi a que melhor respondeu as variações climáticas analisadas.

A quantidade de serapilheira produzida no cerrado sensu stricto indica a diferenciação funcional existente entre os cerradões e as outras fisionomias de cerrado, visto que as últimas produzem menos da metade das quantidades encontradas em cerradões (Silva, dados não publicados; Peres et al. 1983; Delitti 1998). As produções de serapilheira encontradas em cerradão, que é a fisionomia florestal do cerrado, parecem aproximar-se da produção encontrada em outras formações florestais brasileiras (Tab. 3). Porém, até o presente momento, nenhum trabalho comparou estatisticamente as produções de serapilheira entre diferentes fisionomias vegetais brasileiras. Observou-se também, que raramente são publicados os dados brutos de produção mensal de serapilheira, fator que dificulta essa comparação.

A produção de serapilheira em cerradão é estacional, sendo a fração folhas o componente dominante e mais importante nessa dinâmica. Essa fração foi a mais sensível às variações climáticas, visto que se correlacionou negativamente com a umidade do ar, precipitação e temperatura.

Na comparação da produção de serapilheira obtida nesse estudo com a obtida para cerrado (Peres et al. 1983), verificou-se que a produção no cerradão foi significativamente maior, corroborando as observações de Delitti (dados não publicados), de que cerradões podem produzir até o dobro de serapilheira em relação às outras fisionomias de cerrado. Verificou-se também que a produção no cerradão desse estudo não diferiu da produção estimada por Peres et al. (1983) e nem da produção obtida em floresta mesófila semidecídua por Martins \& Rodrigues (1999), indicando que a produção de serapilheira em cerradão realmente parece ser similar à encontrada em formações florestais. Decomposição - A velocidade de decomposição do material foliar nesse estudo mostrou-se consideravelmente mais rápida do que em outras fisionomias de 
cerrado. Delitti (dados não publicados) observou que existe variação considerável entre os valores de decomposição (K) nas diversas fisionomias de cerrado. Santos \& Rodrigues (1982), em estudo realizado em cerrado em Corumbataí (SP), encontraram alto valor de K $(0,51)$ para cerrado, enquanto Delitti (dados não publicados) encontrou valores de $\mathrm{K}$ de 0,25 e 0,29 para um campo cerrado.

Dessa forma, o valor de K $(0,56)$ encontrado para o cerradão neste estudo pode ser considerado alto em comparação com os valores esperados para o cerrado. Guerra-Filho (dados não publicados) encontrou K igual a 0,68 para um cerradão em Tejupá (SP) e Varjabedian \& Pagano (1988) encontraram K igual a 0,83 em mata atlântica no Guarujá (SP). Porém, esses autores calcularam a decomposição para a serapilheira em si, e não somente para a fração folhas, o que resulta em velocidade de decomposição um pouco menor e, conseqüentemente, em valores de K também menores (Swift et al. 1979).

A rápida decomposição que ocorreu no primeiro mês era esperada, visto que é nesse período que ocorrem as maiores perdas de nutrientes e o material está mais palatável aos detritívoros (Swift et al. 1979). Esse primeiro momento parece corresponder à liberação de compostos menos resistentes e/ou mais facilmente lixiviáveis, tais como açúcares e ácidos orgânicos, ao passo que a fase posterior decorre da degradação de estruturas mais resistentes e de compostos mais estáveis e de difícil decomposição, como a lignina e outros compostos fenólicos (Swift et al. 1979). Acredita-se que essa primeira fase seja fortemente influenciada pelas condições climáticas, ma vez que há predominância de processos físicos, que vão se expressar diferentemente de acordo com as características do material em decomposição (Delitti, dados não publicados). O fato de o processo de decomposição ao longo do tempo seguir uma curva do tipo exponencial indica que a decomposição não é constante ao longo do tempo, desde que está ligada a diversos fatores ambientais e químico-físicos do próprio material.

Como o estudo começou ao final da estação seca, a velocidade de decomposição nesses primeiros meses pode ter sido menor do que se tivéssemos iniciado o experimento no período de chuva e de maior umidade, quando se espera que a atividade dos decompositores seja maior. Porém, o alto valor de K encontrado, principalmente para o período de maior produção de serapilheira e consecutivamente anterior ao período de maior produção primária, favorece a fixação de energia, pois a maior parte dos elementos são liberados na época em que sua demanda é mais intensa (Delitti, dados não publicados).

Quanto à decomposição do material foliar, constatou-se que realmente a decomposição é mais rápida no início do processo e que segue um padrão exponencial, visto que ao longo do tempo a composição e a qualidade do material se modificam. Os valores dos coeficientes K e K' obtidos estão de acordo com o observado para comunidades tropicais. Observouse que esses valores são maiores no cerradão, em relação as outras fisionomias do cerrado, sendo, portanto, mais próximos dos valores observados para formações florestais brasileiras.

\section{Agradecimentos}

Ao CNPq e ao PIBIC/UFSCar, pela bolsa de Iniciação Científica concedida ao primeiro autor (Processo 09309/01-4); Celso A. Barbieri Jr. e Mateus H. dos Santos, pela ajuda no trabalho de campo; ao Dr. Marco Antônio Batalha e dois assessores anônimos, pelas sugestões, comentários e revisão do texto.

\section{Referências bibliográficas}

Babbar, L.I. \& Ewol, J.J. 1989. Decomposition del follaje en diversos ecossitemas sucessionales tropicales. Biotropica 21(1): 20-29.

Barros, M.A.G. \& Caldas, L.S. 1980. Acompanhamento de eventos fenológicos apresentados por cinco gêneros nativos do cerrado. Brasil Florestal 42: 7-12.

Bocock, K.L. \& Gilbert, O.J.W. 1957. The disappearance of litter under different woodland conditions. Plant and Soil 9: 179-185.

Borchet, R. 1980. Phenology and ecophysiology of tropical trees: Erythrina poeppigiana. Ecology 61: 1065-1074.

Bray, J.R. \& Gorham, E. 1964. Litter production in forests of the world. Advances in Ecology Research 2: 101-157.

Cesar, O. 1993. Nutrientes minerais na serapilheira produzida na mata mesófila semidecídua da Fazenda Barreiro Rico, Município de Anhembi, SP. Revista Brasileira de Biologia 53(4): 659-669.

Chabot, B.F. \& Hicks, D.J. 1982. The ecology of leaf life span. Annual Rewiew of Ecology and Systematics 13: 229-243.

Dale, J.E. 1982. The growth of leaves. London, Edward Arnold Limited.

Dantas, M. \& Philipson, J. 1989. Litterfall and litter nutrient content in primary and secondary Amazonian "terra firme" rain forest. Journal of Tropical Ecology 5 (1):27-36.

Delitti, W.B.C. 1998. Ciclagem de nutrientes em cerrados. Pp. 1031-1045. In: Anais do VIII Seminário Regional de Ecologia. São Carlos, São Paulo. 
Duvigneaud, P. \& Denayer-De Smet, S. 1969. Biological cycling of minerals in the temperate deciduous forest. Pp. 199-225. In: D.E. Reichle (ed.). Analysis of temperate forest ecosystems. New York, Springer.

Ewel, J.J. 1976. Litter fall and leaf decomposition in a tropical forest succession in eastern Guatemala. Journal of Ecology 64(1): 293-308.

Facelli, J.M. \& Pickett, S.T.A. 1991. Plant litter: its dynamics and effects on plant community structure. The Botanical Rewiew 57: 1-32.

Herrera, R.; Jordan, C.F.; Medina, E.E. \& Klinge, H. 1981. How Humam Activities Disturb Cycles of Tropical Rainforest in Amazonia. Ambio 10(2): 109-114.

Hinkel, R. \& Panitz, C.M.N. 1999. Estudo comparative da produção de serapilheira de uma área de Mata Atlântica e de um povoamento de Pinus elliotti Engelm. var. elliotti na Ilha de Santa Catarina, Brasil. Biotemas 12(1): 67-93.

Hopkins, B. 1966. Vegetation of the Olokemeju Forest Reserve (Nigeria) IV: The litter and soil with special reference to their seasonal changes. Journal of Ecology 54(3): 687-703.

Jackson, J.F. 1978. Seasonality of flowering and leaf-fall in a Brazilian subtropical lower montane moist forest. Biotropica 10(1): 38-42.

Kronka, F.J.N. 1998. Áreas de domínio do cerrado no Estado de São Paulo. São Paulo, Secretaria do Meio Ambiente, São Paulo.

Leitão-Filho, H.F. 1993. Ecologia da Mata Atlântica em Cubatão (SP). São Paulo, EDUNESP/EDUNICAMP, SP.

Mantovani, W. \& Martins, F. 1988. Variações fenológicas das espécies do cerrado da Reserva Biológica de Mogi Guaçu, Estado de São Paulo. Revista Brasileira de Botânica 11: 113-122.

Martins, S.V. \& Rodrigues, R.R. 1999. Produção de serapilheira em clareiras de uma floresta estacional semidecidual no município de Campinas, SP. Revista Brasileira Botânica 22(3): 405-412.

Mason, C.F. 1980. Decomposição. São Paulo, EPU-EDUSP.

Meguro, M.; Vinueza, G.N. \& Delitti, W.B.C. 1979. Ciclagem de nutrientes na Mata Mesófila Secundária, São Paulo, I: Produção e conteúdo de nutrientes minerais no folhedo. Boletim de Botânica da Universidade de São Paulo 7: 11-31.

Meguro, M.; Vinueza, G.N. \& Delitti, W.B.C. 1980. Ciclagem de nutrientes na Mata Mesófila Secundária, São Paulo, III - Decomposição do material foliar e liberação dos nutrientes minerais. Boletim de Botânica da Universidade de São Paulo 8: 7-20.

Monasterio, M. \& Sarmiento, G. 1976. Phenological strategies of plant species in the tropical savanna in the semideciduous forest of the Venezuelen Llanos.Journal of Biogeography 3: 315-346.

Moraes, J.A.P.V.; Perez, S.C.J.G.A. \& Júnior-Carvalho, L.F. 1989. Curso diário e sazonal do potencial de água e resistência estomática em plantas de cerrado.Annals of the Missouri Botanical Garden 27: 13-23.
Moraes, J.A.P.V. \& Prado, C.H.B.A. 1998. Photosynthesis and water relations in cerrado vegetation. Pp.45-63. In: F.R. Scarano \& A.C. Franco (eds.). Ecophysiological strategies of xerophytic and amphibious plants in the neotropics. Rio de Janeiro, Universidade Fedeal do Rio de Janeiro.

Moraes, R.M.; Delitti, W.B.C. \& Struffaldi-De Vuono, Y. 1999. Litterfall and litter nutrient content in two Brazilian Tropical Forests. Revista Brasileira de Botânica 22(1): 9-16.

Morellato, L.P.C.; Rodrigues, R.R.; Leitão-Filho, H.F. \& Joly, C.A. 1989. Estudo fenológico comparativo de espécies arbóreas de floresta de altitude e floresta mesófila semidecídua na Serra do Japí, Jundiaí, SP. Revista Brasileira de Botânica 13: 27-32.

Nimer, E. 1977. Clima. Pp.35-38. In: Geográfica do Brasil. Rio de Janeiro, IBGERJ.

Olson, J.S. 1963. Energy storage and the balance of producers and decomposers in ecological systems. Ecology 44: 322-331.

Pagano, S.N. 1989. Produção de folhedo em mata mesófila semidecídua no Município de Rio Claro, SP. Revista Brasileira de Biologia 49(3): 633-639.

Paulilo, M.T. \& Felippe, G.M. 1992. Crescimento de folhas de árvores de Qualea grandiflora Mart. Revista Brasileira de Botânica 15: 85-93.

Pereira-Silva, E.F.L.; Santos, J.E.; Kageyama, P.Y. \& Hardt, E. 2004. Florística e fitossociologia dos estratos arbustivo e arbóreo de um remanescente de cerradão em uma Unidade de Conservação do estado de São Paulo. Revista Brasileira de Botânica 27(3): 533-544.

Peres, J.R.R.; Suhet, A.R.; Vargas, M.A.T. \& Drozdowics, A. 1983. Litter production in areas of Brazilian "cerrados". Pesquisa Agropecuária Brasileira 18(9): 1037-1043.

Perez, S.C.J.G.A. \& Moraes, J.A.P.V. 1991. Determinações do potencial hídrico, condutância estomática e potencial osmótico em espécies dos estratos arbóreo, arbustivo e herbáceo de um cerradão. Revista Brasileira de Fisiologia Vegetal 3: 27-37.

Pires, A.M.Z.C.R.; Santos, J.E. \& Pires, J.S.R. 2000. Caracterização e diagnóstico ambiental de uma unidade da paisagem. Estudo de caso: Estação Ecológica de Jataí e Estação Experimental de Luiz Antônio. Pp.1-26. In: J.E. Santos \& J.S.R. Pires (eds.). Estudos Integrados em Ecossistemas. Estação Ecológica de Jataí vol. I São Carlos, Rima.

Reich, P. \& Borchet, R. 1984. Water stress and tree phenology in a tropical dry forest in the lowlands of Costa Rica. Journal of Botany 73: 164-174.

Rizzo, J.A.; Centeno, A.J.; Souza, J.S. \& Filgueiras, T.S. 1971. Levantamento de dados em áreas de cerrado e da floresta caducifólia tropical do Planalto Centro-Oeste. Pp. 103-109. In: III Simpósio sobre o Cerrado. São Paulo, Edgard Blucher/EDUSP.

Rochow, J.J. 1974. Litter fall relations in a Missouri Forest. Oikos 25: 80-85. 
Sampaio, E.V.S.B.; Nunes, K.S. \& Lemos, E.E. 1988. Nutrient cycling at Dois Irmãos forest (Recife, Pernambuco, Brasil) through litterfall. Pesquisa Agropecuária Brasileira 23(10): 1055-1062.

Santos, J.E. \& Mozeto, A.A. 1992. Programa de Análise de Ecossistemas e Monitoramento Ambiental: Estação Ecológica de Jataí (Luiz Antônio, SP). In: Ecologia de Áreas Alagáveis de Planície de Inundação do Rio MogiGuaçu. São Carlos, Projeto Jataí. Universidade Federal de São Carlos.

Santos, P.F. \& Rodrigues, G.S. 1982. Avaliação dos métodos para estimativa da decomposição do folhedo em ecossistema de cerrado (Corumbataí-SP). Ciência e Cultura 34(7): 559.

Schilittler, E.H.M.; Marinis, G. \& Cesar, O. 1993. Produção de serapilheira na floresta do Morro do Diabo, Pontal do Paranapanema, SP. Naturalia 18: 135-147.

Scott, D.A.; Proctor, J. \& Thompson, J. 1992. Ecological studies on a lowland evergreen rain forest on Maracá Island, Roraima, Brazil. II. Litter and nutrient cycling. Journal of Ecology 80: 705-717.

Setzer, J. 1966. Atlas Climatológico do Estado de São Paulo. São Paulo, Comissão Interestadual da Bacia do ParanáParaguai, CESP.

Singh, J.S. \& Gupta, S.R. 1977. Plant decomposition and soil respiration in terrestrial ecosystems. The Botanical Review 43: 449-528.

Swift, M.J.; Heal, O.W. \& Anderson, J.M. 1979. Decomposition in terrestrial ecosystems. Oxford, Blackwell Scientific Publications.
Varjabedian, R. \& Pagano, S.N. 1988. Produção e decomposição do folhedo em um trecho de mata atlântica de encosta no município do Guarujá, São Paulo. Acta Botanica Brasilica 1: 243-256.

Vibrans, A.C. \& Sevegnani, L. 2000. Produção de serapilheira em dois remanescentes da floresta ombrófila densa em Blumenau, SC. Revista de Estudos Ambientais 1(2): 103-116.

Villela, D.M. \& Proctor, J. 1999. Litterfall mass and chemistry and nutrient retranslocation in a monodominant forest on Maracá Island, Roraima, Brazil. Biotropica 31(2): 198-211.

Walter, H. 1986. Vegetação e zonas climáticas. São Paulo, EPU.

Werneck, S.M.; Pedralli, G. \& Gieseke, L.F. 2001. Produção de serapilheira em três trechos de uma floresta semidecídua com diferentes graus de perturbação na Estação Ecológica do Tripuí, Ouro Preto, MG. Revista Brasileira de Botânica 24(2): 195-198.

Whittaker, R.H. 1975. Communities and ecosystems . London, Coller-Macmillan.

Witkamp, M. \& Ausmus, B.S. 1976. Process in decomposition and nutrient transfer in forest systems. Pp. 375-396. In: J.M. Anderson \& A. Macfadyen (eds.). The role of terrestrian and aquatic organisms in decomposition process. Oxford, Blackwell Scientific Publications.

Zar, J.H. 1999. Bioestatistical analysis. New Jersey, Prentice Hall. 